\title{
Structure and Magnetic Properties of Granular NiZn-Ferrite - $\mathrm{SiO}_{2}$
}

\author{
Adriana Silva de Albuquerque ${ }^{a, b}$, José Domingos Ardisson ${ }^{a}$, \\ Edison Bittencourt ${ }^{b}$, Waldemar Augusto de Almeida Macedo ${ }^{a}$ \\ ${ }^{a}$ Laboratório de Física Aplicada, Centro de Desenvolvimento da Tecnologia Nuclear, \\ 30123-970 Belo Horizonte - MG, Brazil \\ ${ }^{b}$ Faculdade de Engenharia Química, Universidade Estadual de Campinas, \\ 13083-970 Campinas, SP - Brazil
}

Received: August 15, 1998; Revised: March 30, 1999

\begin{abstract}
Granular systems composed by nanostructured magnetic materials embedded in a non-magnetic matrix present unique physical properties that depend crucially on their nanostructure. In this work, we have studied the structural and magnetic properties of NiZn-ferrite nanoparticles embedded in $\mathrm{SiO}_{2}$, a granular system synthesized by sol-gel processing. Samples with ferrite volumetric fraction $\mathrm{x}$ ranging from $6 \%$ to $78 \%$ were prepared, and characterized by X-ray diffraction, Mössbauer spectroscopy and vibrating sample magnetometry. Our results show the formation of pure stoichiometric NiZn-ferrite in the $\mathrm{SiO}_{2}$ matrix for $\mathrm{x}<34 \%$. Above these fraction, our samples presented also small amounts of $\mathrm{Fe}_{2} \mathrm{O}_{3}$. Mössbauer spectroscopy revealed the superparamagnetic behaviour of the ferrimagnetic NiZn-ferrite nanoparticles. The combination of different ferrite concentration and heat treatments allowed the obtaintion of samples with saturation magnetization between 1.3 and $68 \mathrm{emu} / \mathrm{g}$ and coercivity ranging from 0 to $123 \mathrm{Oe}$, value which is two orders of magnitude higher than the coercivity of bulk NiZn-ferrite.
\end{abstract}

Keywords: granular materials, nanostructures, $\mathrm{NiZn-ferrite} \mathrm{-} \mathrm{SiO}_{2}$, superparamagnetism

\section{Introduction}

Granular magnetic solids (GMS) consisting of magnetic nanosized particles embedded in an immiscible insulating or metallic matrix receive enormous attention nowadays due to new magnetic properties presented by these peculiar structures, like high coercivity and giant magnetoresistance, very attractive for technological applications $^{1}$. In a granular magnetic solid, two main parameters determine the magnetic properties of the composite material: the average diameter of the particles and the volumetric fraction of the magnetic phase. Different systems such as $\mathrm{Fe}, \mathrm{Fe}_{2} \mathrm{O}_{3}$ and $\mathrm{Ni}$, dispersed in insulating matrixes like silica or alumina present considerable changes in the magnetic properties when compared with their equivalent pure bulk materials ${ }^{2-5}$.

$\mathrm{Ni} \mathrm{Zn}$ ferrites, technologically important materials, have spinel configuration based on a face-centred cubic lattice of the oxygen ions, with the unit cell consisting of 8 formula units of the type $\left(\mathrm{Zn}_{\mathrm{y}} \mathrm{Fe}_{1-\mathrm{y}}\right)\left[\mathrm{Ni}_{1-\mathrm{y}} \mathrm{Fe}_{1+\mathrm{y}}\right] \mathrm{O}_{4}$, were the metallic cation in ( ) occupy the tetrahedral sites (A) and the metallic cations in [ ] occupy the octahedral sites $[\mathrm{B}]^{6}$.
Specially due to their broad application in the electronic industry, NiZn ferrites have been extensively studied. Nevertheless, works involving granular systems with NiZn ferrite in insulating matrix have not been sufficiently explored $^{7,8}$.

One ideal route for the synthesis of GMS systems should provide control over particle size and distribution and interparticles spacing. Chemical processes, like solgel, are widely used to produce nanocomposites due to their potential for producing very pure and homogeneous nanostructure with relatively large quantities of final product ${ }^{9}$. In this work, we have investigated the synthesis, by a sol-gel method, of granular $\mathrm{Ni}_{0.5} \mathrm{Zn}_{0.5} \mathrm{Fe}_{2} \mathrm{O}_{4}$ (NiZn-ferrite) embedded in a silica matrix, and studied the structural and magnetic properties of the obtained material.

\section{Experimental}

To obtain granular NiZn-ferrite - $\mathrm{SiO}_{2}$, the precursor sol was prepared by dissolving the nitrates $\mathrm{Ni}\left(\mathrm{NO}_{3}\right)_{2} \cdot 6 \mathrm{H}_{2} \mathrm{O}$, $\mathrm{Zn}\left(\mathrm{NO}_{3}\right)_{2} .6 \mathrm{H}_{2} \mathrm{O}$ and $\mathrm{Fe}\left(\mathrm{NO}_{3}\right)_{3} .9 \mathrm{H}_{2} \mathrm{O}$ in deionized water ( $500 \mathrm{~g}$ nitrates $/ 1 \mathrm{H}_{2} \mathrm{O}$ ) and $\mathrm{Fe}: \mathrm{Ni}: \mathrm{Zn}$ mole proportion equal to $2: 0.5: 0.5$. After mixing the sol solution for $0.5 \mathrm{~h}$, tetrae- 
tylortosilicate (TEOS), $\mathrm{Si}\left(\mathrm{OC}_{2} \mathrm{H}_{5}\right)_{4}$, and drops of concentrated nitric acid were added to the nitrates solution, maintaining the stirring for another $30 \mathrm{~min}$. Nitrates to TEOS molar proportions were chosen in order to form the granular composite $\left(\mathrm{Ni}_{0,5} \mathrm{Zn}_{0,5} \mathrm{Fe}_{2} \mathrm{O}_{4}\right)_{\mathrm{x}}\left(\mathrm{SiO}_{2}\right)_{100-\mathrm{x}}$, where $6 \% \leq \mathrm{x} \leq$ $78 \%$ represents the nominal volumetric fraction of ferrimagnetic NiZn-ferrite in the silica matrix. The gellation of the sol occurred during the drying at $60^{\circ} \mathrm{C}$, for about $20 \mathrm{~h}$. The obtained gel was annealed at 800,1000 and $1100{ }^{\circ} \mathrm{C}$, for $2 \mathrm{~h}$, under ordinary atmosphere.

For the prepared samples, phase analysis were done by $\mathrm{X}$-ray diffraction $(\mathrm{XRD})$ using $\mathrm{Cu}-\mathrm{K} \alpha$ radiation and the sample composition were checked by X-ray fluorescence. The hyperfine properties were investigated by Mössbauer spectroscopy (MS) at room temperature (RT) by using a ${ }^{57} \mathrm{Co}(\mathrm{Rh})$ source and transmission geometry and magnetization measurements were obtained by vibrating sample magnetometry (VSM) at 300, 100 and $4.2 \mathrm{~K}$.

\section{Results and discussion}

Figure 1 (a) shows the XRD patterns of the NiZn-ferrite - $\mathrm{SiO}_{2}$ samples annealed at $800{ }^{\circ} \mathrm{C}$, for $6 \% \leq \mathrm{x} \leq 78 \%$. The decreasing of silica amorphous evidence $\left(2 \theta \approx 23^{\circ}\right)$ and the evolution of crystallinity of the stoichiometric NiZn-ferrite-phase with increasing ferrite content can be seem. For $\mathrm{x}=6 \%$ the material has an amorphous character and for $12 \% \leq \mathrm{x} \leq 34 \%$ the NiZn-ferrite, $\mathrm{Ni}_{0.5} \mathrm{Zn}_{0.5} \mathrm{Fe}_{2} \mathrm{O}_{4}$, is the observed crystalline phase. Starting from $x=41 \%$, occurs the formation of small amount of $\mathrm{Fe}_{2} \mathrm{O}_{3}$, as indicated by the diffraction peak at $2 \theta=33.5^{\circ}$. Similar results were obtained for the samples annealed at 1000 and $1100{ }^{\circ} \mathrm{C}$. The increase of the annealing temperature results in higher crystallization without changes in the obtained Fe-phases, as showed in Fig. 1(b). The average diameter (D) of the ferrite nanoparticles was calculated from the broadening of the (311) XRD-peaks by using the Scherrer equation ${ }^{10}$. The calculated values of $\mathrm{D}$ for different ferrite contents and annealing temperatures are shown in Table 1.

Mössbauer spectra of samples with $6 \% \leq \mathrm{x} \leq 78 \%$, annealed at $800{ }^{\circ} \mathrm{C}$ for $2 \mathrm{~h}$ are shown in Fig. 2a. Samples with $\mathrm{x} \leq 16 \%$ present strong superparamagnetic behaviour due to their small particles size and volumetric fraction and

Table 1. Average diameter $( \pm 3 \mathrm{~nm})$ of the ferrite particles in the NiZn ferrite- $\mathrm{SiO}_{2}$ samples, as determined by XRD, for different ferrite fraction (x) and annealing temperature (T).

\begin{tabular}{lrrrrrrrrr}
\hline $\begin{array}{l}\mathrm{T} \\
\left({ }^{\circ} \mathrm{C}\right)\end{array}$ & \multicolumn{10}{c}{$\mathrm{x}(\%)$} \\
\hline & 6 & 12 & 16 & 25 & 34 & 41 & 52 & 63 & 78 \\
800 & $<6$ & 8 & 9 & 18 & 19 & 23 & 27 & 32 & 40 \\
1000 & $<9$ & 30 & 40 & 46 & 42 & 54 & 56 & 64 & 70 \\
1100 & 15 & 36 & 55 & 60 & 62 & 79 & 85 & 87 & 92 \\
\hline
\end{tabular}

these spectra were fitted to a broad doublet. By increasing the ferrite volumetric fraction the superparamagnetic behaviour decreases, basically due to the growth of the particles diameter and of the interaction between the
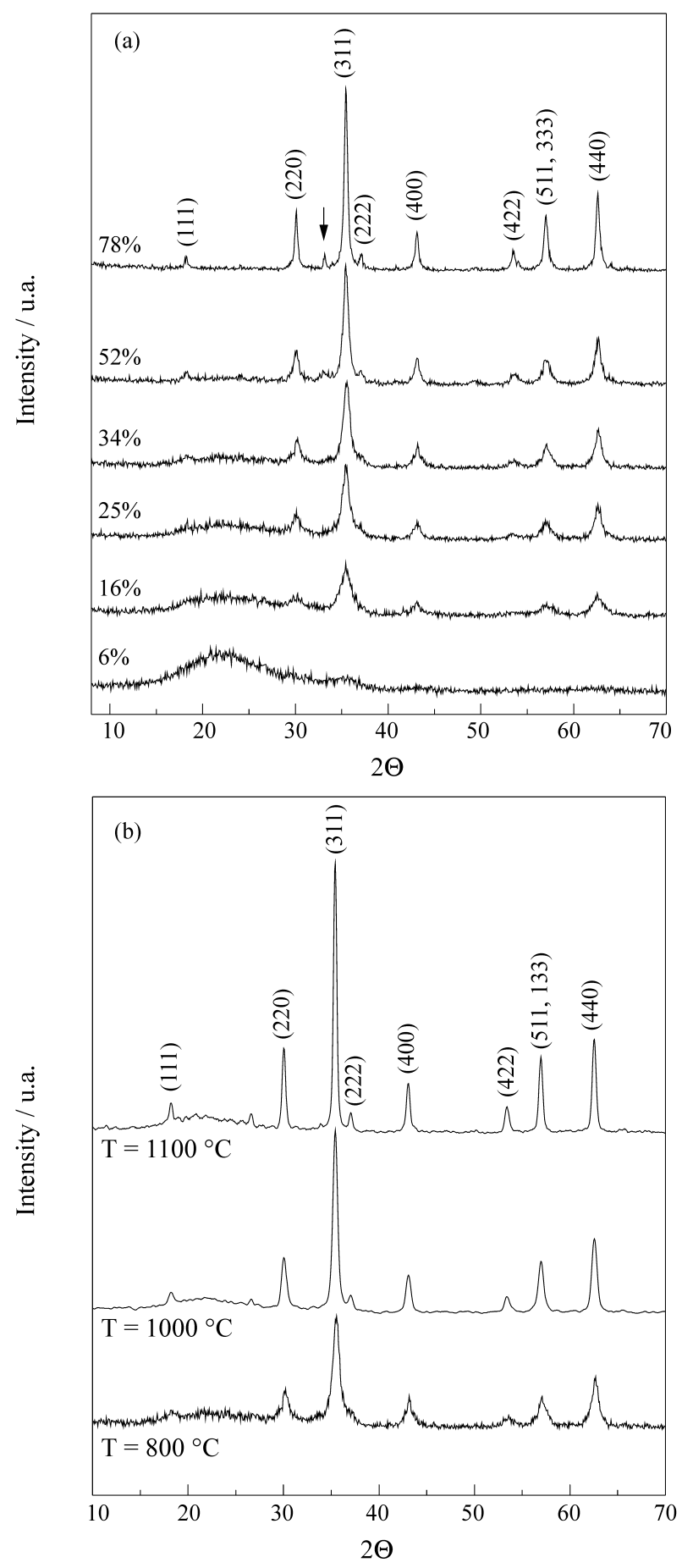

Figure 1. XRD patterns of the samples (a) with different NiZn-ferrite volumetric fractions, after annealing at $800{ }^{\circ} \mathrm{C}$ for $2 \mathrm{~h}$ and (b) with $34 \%$ NiZn-ferrite volumetric fraction, after annealing at 800,1000 and $1100^{\circ} \mathrm{C}$ for $2 \mathrm{~h}$. The NiZn-ferrite peaks are identified and the arrow indicates a $\mathrm{Fe}_{2} \mathrm{O}_{3}$ peak. 
ferrimagnetic ferrite particles. Starting from $x=25 \%$ the spectra were fitted to a broad sextet with linewidth between 0.6 and $0.8 \mathrm{~mm} / \mathrm{s}$, corresponding to $\mathrm{Fe}^{3+}$ at the tetrahedral
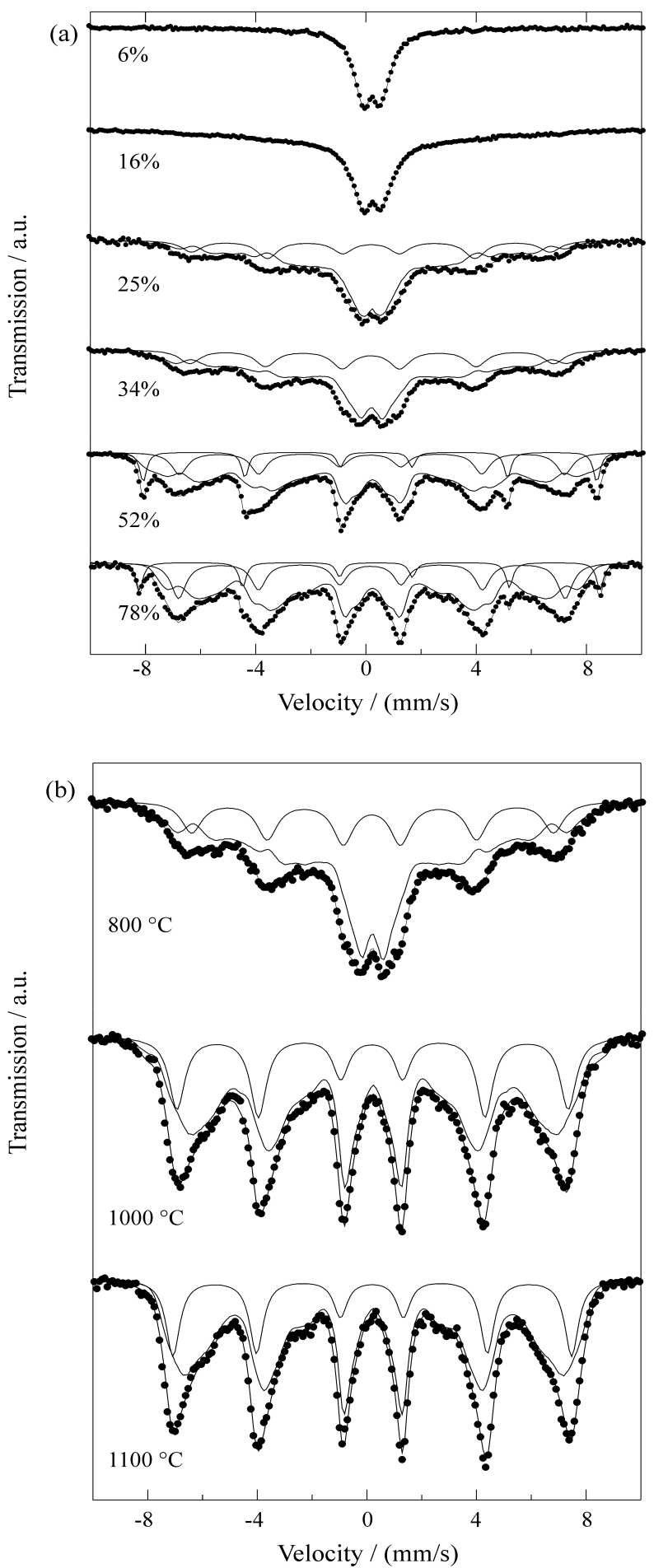

Figure 2. Mössbauer spectra, at RT, of the samples (a) with different NiZn-ferrite volumetric fractions, after annealing at $800^{\circ} \mathrm{C}$ for $2 \mathrm{~h}$ and (b)

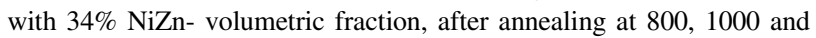
$1100{ }^{\circ} \mathrm{C}$, for $2 \mathrm{~h}$
(A) sites, plus a hyperfine field $\left(\mathrm{B}_{\mathrm{HF}}\right)$ distribution referring to $\mathrm{Fe}^{3+}$ atoms at the octahedral (B) sites. The use of a distribution for fit $B$ sites subspectra is due to the presence of different magnetic neighbours affecting the $\mathrm{Fe}$ atoms distinctly at these sites ${ }^{6,11}$. For these magnetic samples, the peak values of $\mathrm{B}_{\mathrm{HF}}$ are between 40.3 (5) to 44.3 (5) $\mathrm{T}$ for A sites, and vary between 14.4 (5) $\mathrm{T}$ and 41.0 (5) $\mathrm{T}$ for B sites. These values are smaller than the $\mathrm{B}_{\mathrm{HF}}$ of bulk NiZnferrite $^{11}$, indicating the superparamagnetic behaviour of this phase in all samples. In samples with $\mathrm{x} \geq 41 \%$, the subspectra with $\mathrm{B}_{\mathrm{HF}}$ near $51 \mathrm{~T}$ correspond to hematite, in agreement with XRD. As exemplified in Fig. 2-b for samples with $\mathrm{x}=34 \%$, the Mössbauer spectra indicate the evolution of ferrimagnetism with increasing annealing temperature, as expected.

Magnetic properties of all samples were obtained by VSM measurements at 300, 100 and $4.2 \mathrm{~K}$. We have observed large variation of the hysteresis loops for the different ferrite content, as illustrated in Fig. 3 for samples with $6 \%$ and $78 \%$ ferrite submitted to annealing at $800{ }^{\circ} \mathrm{C}$. Fig. 4 shows the change in the saturation magnetization $\left(\mathrm{M}_{\text {sat }}\right)$ and coercivity $\left(\mathrm{H}_{\mathrm{c}}\right)$ with the NiZn-ferrite content for the samples annealed at $800{ }^{\circ} \mathrm{C}$, for different measuring temperatures. $\mathrm{M}_{\mathrm{sat}}$ increases with the ferrite content, as expected, since this parameter depends on the total mass of the material, and with decreasing thermal disorder of the ferrimagnetic nanoparticles. The coercivity maximum observed around $52 \%$ of ferrite can be explained by the appearance of a continuous network of magnetic particles at this ferrite concentration. Above this critical volumetric fraction the material presents bulk-like behaviour. Measurements at 300 and $100 \mathrm{~K}$ indicate that below the percolation limit the system behaves as monodomain particles and $\mathrm{H}_{\mathrm{c}}$ decrease with $\mathrm{D}$. Measurements at $4.2 \mathrm{~K}$ result in

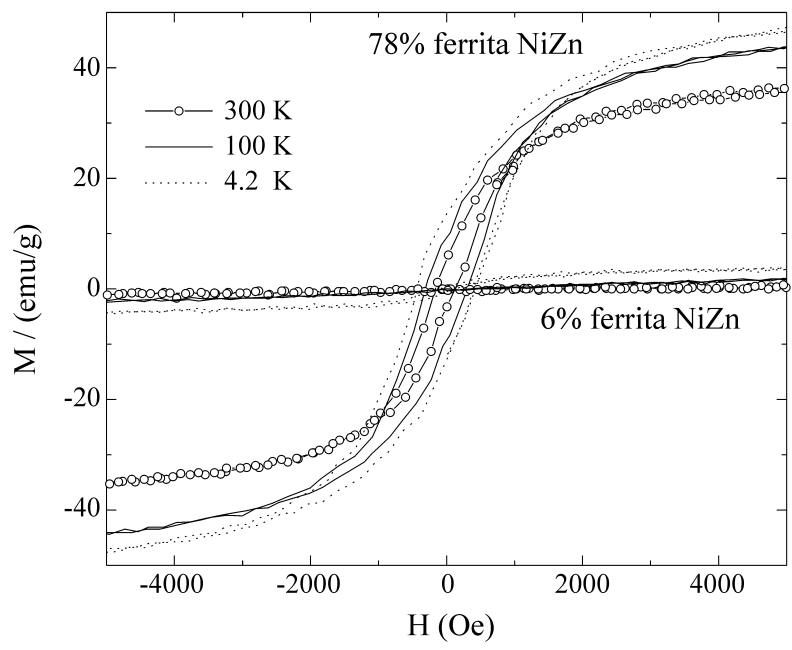

Figure 3. Saturation magnetization $\left(\mathrm{M}_{\mathrm{sat}}\right) v s$. magnetic applied field $(\mathrm{H})$, at 300,100 and $4.2 \mathrm{~K}$, for samples with $\mathrm{NiZn}$-ferrite volumetric fraction (x) equal to $6 \%$ and $78 \%$, annealed at $800{ }^{\circ} \mathrm{C}$, for $2 \mathrm{~h}$. 


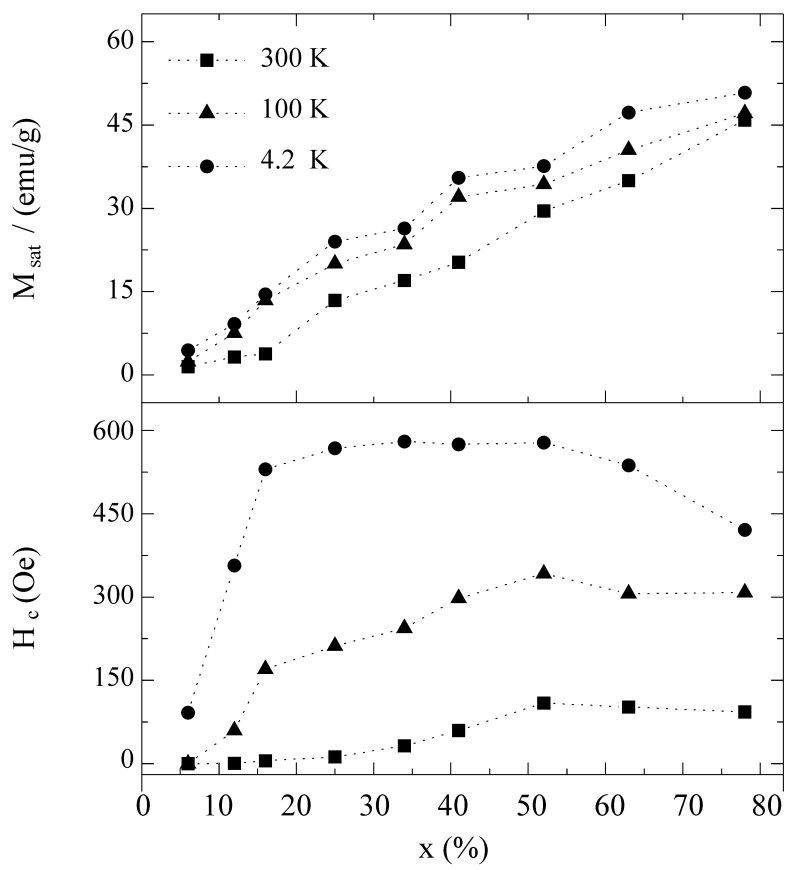

Figure 4. (a) Saturation magnetization $\left(\mathrm{M}_{\mathrm{sat}}\right)$ and $(\mathrm{b})$ coercivity $\left(\mathrm{H}_{\mathrm{c}}\right) v s$. $\mathrm{NiZn}$-ferrite volumetric fraction (x) at 300, 100 and $4.2 \mathrm{~K}$, for the samples annealed at $800^{\circ} \mathrm{C}$, for $2 \mathrm{~h}$.

constant coercivity for samples with $16 \% \leq x \leq 52 \%$, since the thermal effect are very small and, probably, at this range, different $\mathrm{x}$ values do not affect coercivity values. The values of coercivity observed here are 50\% higher than those measured for powders of pure stoichiometric NiZnferrite nanoparticles ${ }^{12}$ and near two orders of magnitude higher than bulk NiZn-ferrite ${ }^{13}$.

\section{Conclusions}

Nanostructured NiZn-ferrite-SiO $\mathrm{S}_{2}$ was successfully synthesized by the sol-gel method followed by annealing at temperatures between 800 and $1100{ }^{\circ} \mathrm{C}$. Samples with NiZn-ferrite particles with average diameters ranging from few nanometers up to $90 \mathrm{~nm}$ were obtained. The results of Mössbauer measurements at room temperature show that the ferrite nanoparticles exhibit superparamagnetic behaviour even after heat treatment at $1100{ }^{\circ} \mathrm{C}$ for $2 \mathrm{~h}$. For the NiZn-ferrite - $\mathrm{SiO}_{2}$ system, it is possible to obtain a large range of tailored magnetic properties through controlled changes in the volumetric fraction and diameter of the ferrimagnetic particles.

\section{Acknowledgments}

The financial support of the CNEN, FAPEMIG and $\mathrm{PADCT} / \mathrm{CNPq}$ are gratefully acknowledged.

\section{References}

1. Chien, C.L. Ann. Rev. Mater. Sci., v. 25, p. 129-160, 1995.

2. Xiao, G.; Liou, S.; Levy, A.; Taylor, J.; Chien, C.L. Phys. Rev. B, v. 34, p. 7573-7577, 1986.

3. Shull, R.D.; Ritter, J.J.; Swatzendruber, L.J. J. Appl. Phys. v. 69, p. 5144-5146, 1991.

4.Estournes, C.; Lutz, T.; Happich, J.; Quaranta, T.; Wissler, P.; Guill, J. J. Magn. Magn. Mater., v. 173, p. 83-92, 1997.

5.Zhang, L.; Papaefthymiou, G.C.; Ziolo, R.F.; Ying, J.Y. Nanostr. Mater., v. 9, p. 185-188, 1997.

6. Dooling, T.A.; Cook, D.C. J. Appl. Phys., v. 69, p. 5352-5354, 1991.

7. Chatterjee, A.; Das, D.; Pradhan, S.; Chakravorty, D. J. Magn. Magn. Mater., v. 127, p. 214-218, 1993.

8. Pal, M.; Brahma, P.; Chakravorty, D.; Bhattavharyya, D.; Maiti, H.S. J. Magn. Magn. Mater., v. 164, p. 256-260, 1993.

9. Peleck, D.L.L.; Rieke, R.D. Chem. Mater., v. 8, p. 1770-1783, 1996.

10. Cullity, B.D. Elements of X-ray Diffraction, AdisonWesley Publ. Company, London, 1967.

11. Arched, M.; Siddique, M.; Anwar-ul-Islam, M.; Butt, N.M.; Abbas, T.; Ahmed, M. Solid. State Commun. v. 93, p. 599-602, 1995.

12. Albuquerque, A.S.; Ardisson, J.D.; Mohallen, N.D.S.; Macedo, W.A.A. Hyp. Int. C, v. 3, p. 256-259, 1998.

13. Smit, J.; Wijn, H.P.J. Wiley, New York, p. 302, 1959. 